\title{
Current Research into Alcohol Problems in Primary Care
}

\author{
Michael B. King, Research Senior Registrar, General Practice Research Unit, Institute of Psychiatry, London SE5
}

In June 1985 a group of researchers involved in the study of alcohol problems in general practice in the UK met informally in York for discussion and exchange of ideas. The meeting was arranged under the auspices of Professor David Robinson of the Addiction Research Centre, Institute for Health Studies of the University of Hull. The group included GPs, psychiatrists, psychologists, sociologists, and other related research workers.

Central to this first meeting was the rapidly changing focus in alcohol studies. As alcohol consumption continues to rise in the UK and other Western countries, alcohol problems assume greater importance both medically and economically. ${ }^{1}$ There has been a move away from hospital and clinic treatment programmes towards intervention at the level of primary care.

The meeting began by reviewing research into the attitudes of GPs to heavy or problem drinkers on their lists. Their attitudes to drinkers, to alcohol treatment facilities, to the usefulness (or otherwise) of intervention, and even to their own consumption of alcohol have all been exhaustively investigated. The response rates by GPs in these studies have often been poor, respondents have been unrepresentative, and little appears to have been done with the information obtained. The group felt that further similar research was unnecessary and that more direct observation of what GPs actually did, although less rigorously 'scientific', may yield more useful results.

Minimal intervention studies with heavy drinkers in general practice are currently underway in both England and Scotland. It has been shown that for psychiatric hospital treatment, minimal intervention on an out-patient basis is at least as effective as prolonged in-patient treatment. ${ }^{2}$ Similar minimal intervention for general medical inpatients with alcohol problems can also be effective. ${ }^{3}$ Intervention in primary care, in similar vein to that for cigarette smoking, ${ }^{4}$ where it was found that simple advice significantly increased the numbers of people giving up, was discussed. The difficulties of studying such intervention were emphasised, including: the possible therapeutic importance of the initial assessments for non-intervention comparison groups; difficulties of follow-up, and the expectations for patients implied by follow-up; and the required number of patients in treatment or comparison groups necessary to show a statistical effect. However, this work was considered exciting and important. If minimal intervention at the level of general practice, proved to be effective, this would undoubtedly jolt many practitioners out of current apathy and even nihilism about alcohol treatment. Defining what is a heavy or at-risk drinker, and determining operational criteria for improvement, were felt to be crucial.

GP identification skills and the uses of screening were considered in detail. Universally agreed levels of safe drinking were urgently called for to counteract the plethora of levels issued by various sources such as the Royal College of Psychiatrists or the Health Education Council. Laboratory tests were generally felt to be unsatisfactory in at-risk individuals because of their low sensitivity. ${ }^{5}$ Screening questionnaires were considered, and it was thought likely that many GPs might involve themselves in more extensive screening in the future, as the emphasis on health prevention grows. It was also felt that GPs needed to be aware that raising alcohol problems with their patients would not always open a classical 'can of worms' that they might feel unable or unwilling to deal with. Most heavy drinkers would not have multiple psychosocial problems, but might well be an at-risk group for these in the future. It was stressed that dependence per se should receive less emphasis in research at the level of primary care as it was not always helpful in deciding intervention strategies, and often diverted attention from at-risk drinkers not yet showing such symptoms.

The complex question of cost-benefit analysis of intervention was raised, and it was pointed out that cost may merely be shifted from one national resource to another, by a concentration of the short-term advantages of intervention. Although preventing early morbidity and mortality, intervention might add to eventual costs to the nation in terms of the increased medical and social load of greater longevity. Simple cost-benefit analysis might be short-sighted, when as yet there was no firm knowledge of what became of at-risk drinkers who reduced their alcohol intake, or abstained altogether. Was there subsequent abuse of other drugs, or might abstention itself lead to social or family imbalance resulting in other psychological or social problems? The consensus of the group remained, however, that a reduction in alcohol consumption, rather than abstention, was the goal for most at-risk drinkers, and this was known to have at least short-term advantages in terms of social, emotional, and physical functioning.

For the future, the issues of problem drinking were stressed as part of a wider concern with health. Primary care teams should be seen to involve themselves in areas such as smoking, exercise, diet and so forth, as part of a prevention package. The group felt that a large multicentre intervention trial for at-risk drinkers in general practice might be the next important step. In the light of this, the 
outcome of the current minimal intervention studies was eagerly awaited.

\section{REFERENCES}

'Smith, R. (1982) Alcohol Problems-ABC of Alcohol and Alcoholism. London: British Medical Association.

2Edwards, G., Orford, J., Egert, S., Guthrie, S., HaWker, S., Hensman, C., Mitcheson, M., Oppenheimer, E. \& Taylor, C. (1977) Alcoholism: a controlled trial of 'treatment' and 'advice'. Journal of Studies on Alcohol, 38, 1004-1031.
${ }^{3}$ Chick, J., Lloyd, G. \& Crombie, E. (1985) Counselling problem drinkers in medical wards: a controlled study. British Medical Journal, 290, 965-967.

${ }^{4}$ Russell, M. A. H., Wilson, C., Taylor, C. \& Baker, C. D. (1979) Effect of general practitioners' advice against smoking. British Medical Journal, ii, 231-235.

5Johnson, R. D. \& Williams, R. (1985) Prevention of hazardous drinking: the value of laboratory tests. British Medical Journal, 290, 1849-1850.

\section{College Prizes, Medals and Travelling Fellowships}

Gaskell Medal and Prize

This is considered to be one of the foremost academic distinctions in psychiatry. The value of the Prize is $£ 500$, and is awarded on the results of an annual examination, which will be held next in June 1986. Candidates should be qualified medical officers with a minimum of two years' service in mental hospitals or clinics in psychiatry in the United Kingdom or elsewhere in the British Commonwealth; they should be between 23 and 35 years of age and possess the MRCPsych or any other degree or diploma in psychological medicine.

Application forms are obtainable from the Education Department at the College and should be completed and returned not later than 31 March 1986, enclosing an entry fee of $£ 5.00$, which is returnable to bona fide candidates.

\section{Laughlin Prize}

This Prize is awarded twice a year to the candidate who obtains the highest mark and the best recommendation from the Examiners in the Membership Examination. The value of the Prize is currently $£ 50$.

\section{Research Prize and Bronze Medal}

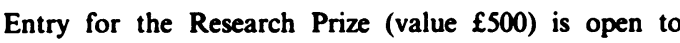
Members or Inceptors of the College below the rank of consultant psychiatrist. The research should be presented in the form of an essay or dissertation, with tables or figures, may incorporate previously published work and may involve collaboration with other workers, provided that this is clearly indicated and attributed. Entries should be sent to the Dean of the College by 31 March 1986.

\section{Peter Scott Memorial Scholarship}

An award of up to $£ 1000$ is made biennially to members of the medical profession or medical students wishing to further their studies in the field of forensic psychiatry or delinquency. Application forms are available from the Education Department and should specify the proposed activity to be funded-research, travel to other centres, writing, etc. The closing date for return of completed forms is 31 March 1986.

\section{Natalie Cobbing Travelling Fellowship}

A biennial award of $£ 2000$, for travel to centres overseas, is available to further the training of specialists in the psychiatry of mental handicap. Applicants must possess the MRCPsych, be under the age of $\mathbf{4 0}$ and of senior registrar or consultant status (the latter within three years of appointment) working in the UK or the Republic of Ireland. They should submit a curriculum vitae; the names of two referees; a proposal as to how their time abroad will be spent, together with confirmation if possible from the host centres; and an account of original research, published or unpublished papers or reviews in the field of mental handicap or psychiatry. The closing date for application is 31 March 1986.

\section{Squibb Travelling Fellowship}

The Fellowship, value $£ 5000$, is awarded for travel abroad to one or two centres, and is open to Members of the College working in the UK or the Republic of Ireland of senior registrar or lecturer grade, or consultants within the first three years of their appointment. Applications, stating nature of study abroad, with confirmation from the host centre(s), should be sent to the Dean of the College by 30 April 1986. (Full details of the Fellowship appeared in the Bulletin, January 1986, 10, 13.)

Further details of all Prizes and Fellowships are obtainable from the Education Department at the College.

\section{Exemption from Part II of the Membership of the Royal College of Physicians of Ireland}

At a recent meeting of the Royal College of Physicians of Ireland, it was agreed that some qualifications be recognised which would give exemption from Part II of the examination under By-law 18. One of the qualifications is the Membership of the Royal College of Psychiatrists. 